\title{
Análise dos antecedentes do comportamento de cidadania organizacional: estudo de caso com servidores de uma instituição federal de ensino
}

o Comportamento de Cidadania Organizacional (CCO) é definido como um comportamento individual, espontâneo e criativo, em que o funcionário vai além do que é exigido pelo seu cargo. Este tipo de comportamento promove os objetivos da organização e ainda melhora o ambiente social e psicológico no qual a tarefa é executada. O objetivo deste trabalho foi de investigar qual a influência do comprometimento afetivo e dos suportes organizacional e social sobre o Cco de servidores públicos de uma instituição federal de ensino. Essa pesquisa teve um caráter quantitativo, sendo aplicado um questionário do tipo survey numa amostra de 310 servidores públicos. Os dados foram analisados usando-se o software Statistical Package for the Social Sciences (SPSS) e os resultados indicaram que o CCO é influenciado mais fortemente pelo comprometimento afetivo do que pelo suporte organizacional e social. Entretanto, o fator cooperação sofreu uma influência mais preponderante do suporte social.

Palavras-chave: Cidadania Organizacional; Comprometimento Afetivo; Suporte Organizacional; Suporte Social; Serviço Público.

\section{Background analysis of organizational citizenship behavior: case study with employees of a federal educational institution}

Organizational Citizenship Behavior ( $\mathrm{CCO}$ ) is defined as individual, spontaneous and creative behavior in which the employee goes beyond what is required by his or her job. This type of behavior furthers the goals of the organization and further enhances the social and psychological environment in which a task is performed. The objective of this work was to investigate the influence of the affective and social impairment of sports and organization on the CCO of public servants of a federal educational institution. This research had a quantitative character, being applied a survey type questionnaire in a sample of 310 civil servants. Data were analyzed using the Statistical Package for Social Sciences (SPSS) software and the results indicate that BCC is more strongly influenced by the affective impairment of organizational and social support. However, the factor of cooperation is influenced more by social support.

Keywords: Cidadania Organizacional; Comprometimento Afetivo; Suporte Organizacional; Suporte Social; Serviço Público.

Topic: Comportamento Organizacional

Reviewed anonymously in the process of blind peer
Received: 10/07/2019

Approved: 12/09/2019
Kenny Moreno Santos Fernandes

Universidade Federal dos Vales do Jequitinhonha e Mucuri, Brasil http://lattes.cnpq.br/55081477335592968

kennymorenos@gmail.com

Lívia Maria de Pádua Ribeiro (iD)

Centro Federal de Educação Tecnológica de Minas Gerais, Brasil

http://lattes.cnpq.br/3836203930867479

http://orcid.org/0000-0002-5271-9397

livia.padua2014@gmail.com
Referencing this:

FERNANDES, K. M. S.; RIBEIRO, L. M. P.. Análise dos antecedentes do comportamento de cidadania organizacional: estudo de caso com servidores de uma instituição federal de ensino. Revista Brasileira de Administração Científica, v.10, n.3, p.106-121, 2019. DOI: http://doi.org/10.6008/CBPC2179-684X.2019.003.0009 


\section{INTRODUÇÃO}

Diante de um cenário de constantes mudanças, devido, principalmente, à globalização e ao desenvolvimento tecnológico, novas formas de organização do trabalho foram sendo construídas com o intuito de tornar as empresas cada vez mais produtivas, competitivas e eficientes. Essas novas formas organizacionais têm sido caracterizadas pela adoção de abordagens mais participativas na tomada de decisão, desenvolvimento de trabalho em equipe, maior autonomia, incentivo à qualificação dos trabalhadores, e ainda, o incentivo ao compartilhamento de conhecimentos entre os membros da organização (DEKAS, 2010; BOREHAM et al., 2013).

Nesse novo contexto, as organizações têm descoberto que identificar habilidades e competências na realização das tarefas é somente o início para se conseguir um desempenho eficaz. Segundo Katz et al. (1974) ter em seu quadro de pessoal funcionários que se empenham além do que está previsto no seu contrato de trabalho, apresentando comportamentos definidos como de Cidadania Organizacional (CCO) passou a ser elemento de diferenciação para as empresas (KATZ et al., 1974; PODSAKOFF et al., 2000), inclusive para aquelas que são públicas (COHEN et al., 2000; RAYNER et al., 2012).

Os estudos sobre Comportamentos de Cidadania Organizacional têm buscado explicar porque alguns funcionários executam apenas o que está descrito no seu contrato formal de trabalho enquanto outros apresentam, de forma espontânea, comportamentos benéficos à organização e que não possuem garantia de recompensa. De acordo com Organ (1988), estes comportamentos são discricionários e voluntários, caracterizados por um conjunto de condutas interpessoais, que constituem a base de sustentação do ambiente social e psicológico no qual a tarefa é desempenhada (ORGAN, 1988).

Considera-se, portanto, que o Comportamento de Cidadania Organizacional pode sofrer influência do contexto social onde o trabalho é realizado. Nesse sentido, algumas pesquisas (KAMDAR et al., 2007; RHOADE et al., 2002), têm demonstrado que a qualidade das relações sociais e de apoio desencadeiam comportamentos como os de cidadania organizacional (KIM et al., 2013).

A análise do contexto social das organizações coloca em evidência os Suportes Social e Organizacional, pois são variáveis que contribuem para a compreensão das interações dos indivíduos no ambiente de trabalho. A percepção de suporte organizacional caracteriza-se como um importante aspecto psicológico presente nas relações de trabalho, sendo definida como a percepção que o indivíduo tem do quanto a organização valoriza as suas contribuições e cuida do seu bem-estar (EISENBERGUER et al., 1990).

Em complementação ao Suporte Organizacional tem-se o Suporte Social, que está relacionado com o grau com que os indivíduos percebem que possuem relações sociais positivas com os outros. A literatura tem indicado que os aspectos sociais presentes na organização influenciam os afetos no trabalho, aumentando o comprometimento com a organização. Por sua vez, o nível de comprometimento dos funcionários pode influenciar a disposição destes para se engajarem em atividades cooperativas, como os comportamentos de cidadania organizacional (COSTA et al., 2014). 
Alguns estudos (WILLIANS et al., 1991; SIQUEIRA, 1995) estabeleceram a relação entre os comportamentos de cidadania organizacional (CCO) e o Comprometimento Afetivo (CA), considerando o CA como um antecedente dos CCO. Da mesma forma, o construto Suporte Organizacional (SO) aparece em outros estudos (LEAL, 2014; FERNANDES et al., 2014) relacionado ao CA; bem como outras pesquisas também relacionam o Suporte Organizacional com os CCO (CHEN et al., 2009).

Entretanto, a literatura ainda carece de estudos que relacionem os três construtos (SO, CA e CCO), por isso este trabalho teve como objetivo relacionar os três construtos, verificando os índices de correlação entre as suas dimensões e como as variáveis do SO e do CA impactam o CCO. Para se atingir este objetivo busca-se responder a seguinte pergunta de pesquisa: 'Qual a influência do comprometimento afetivo e dos suportes organizacional e social sobre o comportamento de cidadania organizacional?'.

Este estudo encontra-se estruturado em mais cinco seções, além desta introdução. Na seção dois, está o referencial teórico adotado. Em seguida, na seção três encontra-se os aspectos metodológicos, relacionados à coleta e análise dos dados. Na seção quatro estão os resultados e na seção cinco, a análise dos dados acerca do estudo realizado. E finalmente, na seção seis estão as considerações finais da pesquisa.

\section{REVISÃO TEÓRICA}

No referencial teórico apresenta-se os resultados sobre o tema a ser pesquisado, tendo como ponto de partida estudos realizados por outros autores. Esta revisão facilita a formulação de suposições e oferece suporte adequado à interpretação dos dados coletados no campo. Assim, esta seção destina-se a fundamentar o trabalho sobre o assunto proposto, dando consistência à investigação e maior familiarização com o tema.

\section{Cidadania Organizacional}

A definição mais usual de Cidadania Organizacional é a apresentada por Organ (1988), que conceitua cidadania como um comportamento individual, discricionário, não explicitamente reconhecido pelo sistema formal de recompensas, e que contribui para o funcionamento eficaz da organização. O autor ainda, reforça que esse tipo de comportamento também pode ser considerado como um tipo de conduta interpessoal e voluntária, sustentada pelo ambiente social onde a tarefa é desempenhada (ORGAN, 1988).

Embora Organ (1988) tenha proposto a definição para cidadania organizacional, foram os autores Katz et al. (1974) o primeiro a evidenciar a importância dos atos de cidadania para as organizações. Segundo os autores os comportamentos de cidadania organizacional (CCO) são determinados como gestos espontâneos e cooperativos, não prescritos nas obrigações formais da tarefa, e têm sua origem no vínculo que se estabelece entre o funcionário e a organização, ou seja, é na relação com a organização, a partir do exercício dos seus direitos e deveres que a cidadania pode emergir (KATZ et al., 1974).

Com o reconhecimento da importância do comportamento de cidadania no contexto organizacional, principalmente a partir da década de 80, surge o interesse por parte dos pesquisadores para se investigar as dimensões, os antecedentes e os consequentes deste construto. O desenvolvimento da área, no entanto, 
ocorreu em virtude de os estudos empíricos realizados terem apontado a existência de uma correlação positiva entre a emissão de CCO e eficácia e o sucesso organizacional (PODSKOFF et al., 2000).

De acordo com Katz et al. (1974) cinco itens compõem o construto: atividades de cooperação com os demais membros da organização, ações protetoras ao sistema, apresentação de sugestões criativas para a melhoria organizacional, autotreinamento para maior responsabilidade, e criação de um clima favorável para a organização no ambiente externo. Outros estudos se seguiram ao de Katz et al. (1974), fazendo surgir outras dimensões como, altruísmo, conscienciosidade, desportivismo, lealdade, entre outras. De acordo com Podsakoff et al. (2000), existem na literatura mais de 30 diferentes dimensões para cidadania organizacional, refletindo numa dificuldade para a sua dimensionalidade.

Segundo Williams et al. (1991), o CCO pode ser classificado em duas categorias: Comportamentos de Cidadania Organizacional orientados para a organização (CCO-O), e Comportamentos de Cidadania Organizacional orientados para os indivíduos (CCO-I). Apontando nesse mesmo sentido está o estudo desenvolvido por Dyne et al. (1995), que divide os CCO em comportamentos orientados para a afiliação e os comportamentos orientados para o desafio. Os CCO orientados para a afiliação possuem natureza interpessoal e cooperativa, e se expressam no relacionamento com os outros. Já os CCO orientados para o desafio, estão relacionados aos desafios construtivos, que tem o objetivo de melhorar a organização e alterar o status quo (PODSAKOFF et al., 2014).

Em se tratando de estudos no âmbito nacional, o destaque são os trabalhos de Siqueira $(1995,2003)$ e Porto et al. (2003). Siqueira (1995) é considerada a precursora do tema no país, sendo a autora a responsável pelo desenvolvimento e validação da primeira escala para medir os comportamentos de cidadania organizacional. A escala utilizada por Siqueira (1995) está baseada nas cinco dimensões do comportamento inovador e espontâneo de Katz et al. (1974).

No entendimento da autora os estudos sobre CCO deveriam se voltar para as dimensões propostas inicialmente por Katz et al. (1974), tendo em vista que os CCO são entendidos como atos, as suas dimensões devem expressar atitudes, ações; e não aspectos da personalidade individual como lealdade e altruísmo. Além do desenvolvimento da escala, Siqueira (2003) também apresenta uma nova conceituação para o construto, que serviu de base para este estudo. Em sua definição, a autora evidencia a importância do contexto social para a ocorrência do comportamento de cidadania organizacional. Segundo Siqueira (2003),

Os comportamentos de cidadania organizacional são atos de troca social, oferecidos voluntariamente pelos trabalhadores às organizações. Eles constituem gestos de colaboração espontânea que, isentos de prescrições legais ou contratuais, permitem, dentro de uma relação social com a organização, iniciar uma permuta de atos extra papéis funcionais por possíveis ou futuras retribuições sociais, materiais ou econômica.

O conceito apresentado tem duas características principais. Primeiramente, essa definição reforça a noção de que a cidadania deve ser entendida como gestos eminentemente voluntários (espontâneos) dos funcionários, podendo ou não serem retribuídos pelo empregador; num segundo momento, fica evidenciado a importância do aspecto relacional para a consecução desses atos, tendo como referência a relação de troca entre funcionário e organização (SIQUEIRA, 2003). 
Dessa forma, o contexto organizacional onde os funcionários estão inseridos, constitui o meio pelo qual se recebe apoio e suporte, e influencia o modo como estes executam o seu trabalho. As relações sociais vivenciadas no ambiente de trabalho enfatizam a percepção de que o suporte é um componente importante, e que pode interferir nos resultados organizacionais (COSTA et al., 2014).

\section{Suporte Organizacional e Suporte Social}

A Percepção de Suporte Organizacional (PSO) está diretamente relacionada às crenças e expectativas do indivíduo acerca da retribuição e do reconhecimento dado pela organização na qual está inserido. Segundo Eisenberger et al. (1990), a PSO é composta por crenças globais sobre o quanto a organização se preocupa com o bem-estar e valoriza as contribuições de seus funcionários (EISENBERGER et al., 1990).

As organizações costumam valorizar os empregados que demonstram estar comprometidos, envolvidos, e que possuem dedicação e lealdade com a organização e com o trabalho. Por outro lado, os empregados buscam organizações que proporcionem a eles um bom ambiente de trabalho. Para Siqueira et al. (2004), a PSO impacta diretamente na vida organizacional, e define-se como uma relação de troca entre a organização e o empregado, por meio de um esquema mental de reciprocidade (SIQUEIRA et al., 2004).

Segundo Eisenberguer et al. (1990), a percepção de suporte organizacional ocorre a partir de um processo de personificação da organização, revelando que os funcionários atribuem às atitudes dos agentes organizacionais como se fossem ações da própria organização. Nesse caso, o funcionário só desenvolve percepções favoráveis quanto ao suporte organizacional quando julga que as retribuições organizacionais são sinceras, com boas intenções e livres de manipulação (EISENBERGUER et al., 1990; OLIVEIRA-CASTRO et al., 1999).

Ao investigarem a estrutura do suporte organizacional, Oliveira-Castro et al. (1999) desenvolveu uma medida composta por quatro dimensões: gestão do desempenho, carga de trabalho, suporte material e ascensão, promoção e salários. A partir dessas dimensões, Pinheiro (2002) propôs a inclusão de mais dois itens: gestão da chefia e suporte social no trabalho (apoio dos colegas). Essas duas dimensões adicionais buscam abarcar a dimensão relacional contida no suporte. Dessa forma, o construto suporte organizacional fica composto por dois fenômenos distintos, a percepção de suporte organizacional e a percepção de suporte social no ambiente de trabalho (OLIVEIRA-CASTRO, 1999; PINHEIRO, 2002). No presente estudo, são considerados os dois tipos de suporte, conforme apontado por Pinheiro (2002).

Apesar de as percepções de suporte organizacional e suporte social se referirem a agentes diferentes, a organização em si para o primeiro e o apoio dos colegas e da chefia para o segundo, os dois fenômenos podem ser considerados complementares e podem ser considerados como a percepção do funcionário sobre as características e as condições de trabalho (PASCHOAL et al., 2010).

O Suporte Organizacional e o Suporte Social têm sido relacionados com diversos fenômenos para a efetividade organizacional. Segundo Oliveira-Castro et al. (1999), a literatura especializada no assunto vem mostrando a existência de correlações positivas entre o suporte organizacional e medidas do desempenho no trabalho e do comportamento de cidadania organizacional. 
Com base nessas informações, é possível elaborar as primeiras hipóteses desse estudo: H1: A Percepção de Suporte Organizacional está positivamente e significativamente relacionada com o Comportamento de Cidadania Organizacional; e H2: A Percepção de Suporte Social está positivamente e significativamente relacionada com o Comportamento de Cidadania Organizacional.

Estudos em torno dessa temática também têm sinalizado que o suporte organizacional pode contribuir com o alcance de melhores resultados para a organização, como por exemplo, o aumento do comprometimento afetivo (RHOADES et al., 2002; SIQUEIRA, 2003). Apontando nesse mesmo sentido, uma pesquisa realizada por Siqueira (2003) confirmou que a percepção de suporte organizacional constitui um forte antecedente do comprometimento afetivo, destacando que, o vínculo afetivo com a organização tende a se tornar mais evidente à medida que os empregados percebem a empresa comprometida com eles.

Considerando tal relação, é possível elaborar outras duas hipóteses para este trabalho: H3: A Percepção de Suporte Organizacional está positivamente e significativamente relacionada com o Comprometimento Afetivo; e H4: A Percepção de Suporte Social está positivamente e significativamente relacionada com o Comprometimento Afetivo.

\section{Comprometimento Afetivo}

Os indivíduos desenvolvem diferentes vínculos com seus pares, organizações e grupos de trabalho, determinando a natureza das relações que se estabelecem. Uma das formas de se entender estes vínculos é por meio do comprometimento do indivíduo com a organização. No ambiente organizacional, a compreensão do comprometimento é fundamental, pois permite conhecer a relação de compromisso entre o indivíduo e a empresa (SIQUEIRA et al., 2004).

O comprometimento afetivo é reconhecido como o resultado das trocas realizadas entre o indivíduo e a organização, e vai muito além de uma lealdade passiva, porque se efetiva por meio de um relacionamento ativo e que tem como consequência o bem-estar dos sujeitos. Segundo Bastos (1996) o comprometimento de natureza afetiva é um processo no qual o indivíduo se identifica com os objetivos e valores organizacionais, refletindo em sentimentos de estima ou na emissão de comportamentos (BASTOS, 1996).

De acordo com Meyer et al. (1993), o comprometimento afetivo é composto por três dimensões: uma forte crença e aceitação dos objetivos e valores organizacionais; disposição em exercer um esforço considerável em prol da organização; e um forte desejo em permanecer na organização. A premissa básica do enfoque afetivo do comprometimento é a identificação do funcionário com os objetivos organizacionais e a introjeção dos valores, a partir de um sentimento de lealdade, vontade de permanecer e se esforçar pela organização, caracterizada pela expressão “vestir a camisa da empresa" (FOSSÁ, 2003).

Ao experimentar vivências positivas em relação à organização, e que sejam consistentes com suas expectativas e que, ainda, satisfaçam as suas necessidades básicas, os funcionários tendem a desenvolver uma forte base afetiva, um certo apego à organização. Meyer et al. (1993), afirmam que o comprometimento afetivo se relaciona negativamente com comportamentos indesejáveis, como a intenção de deixar a 
organização e o absenteísmo, e positivamente com comportamentos desejáveis, como os de cidadania organizacional (MEYER et al., 1993).

Estudos desenvolvidos por Siqueira (2003), Williams et al. (1991) e Martins et al. (2015), também apontam para uma correlação positiva entre comprometimento afetivo e cidadania organizacional. Segundo Siqueira (2003), o comprometimento afetivo figura como um antecedente dos atos de cidadania organizacional. Em seu modelo pós-cognitivo, a autora defende que as variáveis afetivas são os sentimentos positivos que emergem no ambiente de trabalho e que favorecem a emissão de gestos de cidadania no ambiente organizacional (SIQUEIRA, 2003).

Dessa forma, é possível elaborar mais uma hipótese deste trabalho: H5: O Comprometimento Afetivo está positivamente e significativamente relacionado com o Comportamento de Cidadania Organizacional. Ainda, segundo Siqueira (2003), os cinco fatores que compõem o Comportamento de Cidadania Organizacional estão mais fortemente associados às variáveis afetivas do que às variáveis cognitivas. Em seu modelo pós-cognitivo não foi encontrada nenhuma correlação entre os fatores de cidadania e a percepção de suporte organizacional. Tendo em vista esta afirmação de Siqueira (2003), apresenta-se a última hipótese deste estudo: H6: Os cinco fatores de cidadania organizacional estão mais fortemente associados ao Comprometimento Afetivo do que aos Suportes Organizacional e Social.

\section{METODOLOGIA}

Tendo por meta atingir os objetivos propostos neste estudo, realizou-se uma pesquisa de caráter descritivo e quantitativo, utilizando-se para isso de um questionário do tipo survey, com o intuito de coletar dados primários a partir das informações fornecidas por um grande número de pessoas (FREITAS, 2000; HAIR et al., 2009).

A estratégia de pesquisa adotada foi o estudo de caso realizado junto aos funcionários de uma Instituição Federal de Ensino no Estado de Minas Gerais. A população alvo foi de 1.650 servidores (conforme Relatório de Gestão 2015). O questionário na sua forma física foi distribuído para aproximadamente 500 servidores, entre professores e técnicos administrativos dos Campi I e II na cidade de Belo Horizonte; e na sua forma eletrônica foi enviado um link, por meio do site Survey Monkey, para os servidores das Unidades do Interior (Araxá, Contagem, Curvelo, Divinópolis, Leopoldina, Nepomuceno, Varginha e Timóteo).

Dos questionários em sua forma física houve um retorno de 206 respondentes, destes 4 foram eliminados por apresentarem erro de preenchimento; dos questionários online foram obtidas 116 respostas, sendo que deste valor foram eliminados 08 questionários com problemas no preenchimento das informações. Dessa forma, para esta pesquisa obteve-se um total válido de 310 questionários, número suficiente diante do cálculo amostral. As respostas ao questionário foram dadas em uma escala do tipo Likert de 5 pontos ( 1 = Nunca; 2 = Raramente; 3 = Algumas Vezes; 4 = Frequentemente; 5 = Sempre).

Como método de coleta de dados foi utilizado um questionário contendo questões adaptadas de escalas validadas: Escala de Comportamento de Cidadania Organizacional (ECCO): utilizou-se como base para este questionário as escalas desenvolvidas por Siqueira (1995), por Porto et al. (2003) e Siqueira et al. (2014), 
o que resultou num instrumento composto por 24 itens distribuídos em 5 fatores, sendo eles: Defesa da Organização com 7 itens, Apresentação de Sugestões Criativas com 6 itens, Proteção ao Sistema com 4 itens, Autotreinamento com 3 itens; e Cooperação com os Colegas com 4 itens.

Escala de Comprometimento Afetivo (ECOA): foi utilizada a escala desenvolvida por Siqueira (1995), na sua versão reduzida, composta por 5 itens; Escala de Suporte Organizacional Percebido (ESOP): para este estudo foram utilizados algumas variáveis da escala desenvolvida por Tamayo et al. (2010), do total de seis fatores da escala original foram utilizados 4 fatores, sendo eles: Suporte Material com 5 itens, Sobrecarga de Trabalho com 4 itens, Estilos de Gestão da Chefia com 7 itens; e Apoio dos Colegas com 6 itens. Esclarece-se que os fatores Suporte Material e Sobrecarga de Trabalho compõem a escala de Suporte Organizacional, e os fatores Estilo de Gestão da Chefia e Apoio dos Colegas constituem a escala de Suporte Social. Então, a escala ESOP é uma escala que agrega o Suporte Organizacional e o Social em uma mesma escala.

A análise dos dados foi conseguida com o apoio do Software SPSS (Statistical Package for the Social Sciences) versão 17.0 para Windows, sendo realizados os testes estatísticos da Análise Fatorial Exploratória e da Correlação de Pearson. A Análise Fatorial Exploratória teve o objetivo de agrupar as variáveis em fatores, sendo que cada fator representava uma dimensão latente do construto. Optou-se, então, por adotar a análise dos componentes principais como método de extração das dimensões e como método de rotação utilizouse a Varimax, esse procedimento minimizou o número de variáveis em cada fator, e contribuiu para uma melhor interpretação dos fatores (HAIR et al, 2009). Também foram calculados os índices de confiabilidade (Alfa de Cronbach) de cada escala utilizada no estudo.

Já a Correlação de Pearson é um teste estatístico que informa o tipo de associação linear existente entre as variáveis consideradas. As correlações de Pearson têm o objetivo de medir a intensidade e a direção da associação entre duas variáveis quantitativas. O coeficiente de correlação pode variar entre -1 e 1, e divide-se em quatro categorias: fracas quando inferiores a 0,25; moderadas entre 0,25 e 0,5; fortes entre 0,5 e 0,75; e muito fortes quando iguais ou superiores a 0,75 (MAROCO, 2011).

Para facilitar a compreensão acerca desta pesquisa, apresenta-se na Figura 1 o Modelo Teórico e baseado neste modelo e na revisão bibliográfica, foram elaboradas seis hipóteses da pesquisa, que irão proporcionar a interpretação dos resultados do estudo de campo realizado, com o objetivo de testar a validade empírica de cada hipótese proposta.

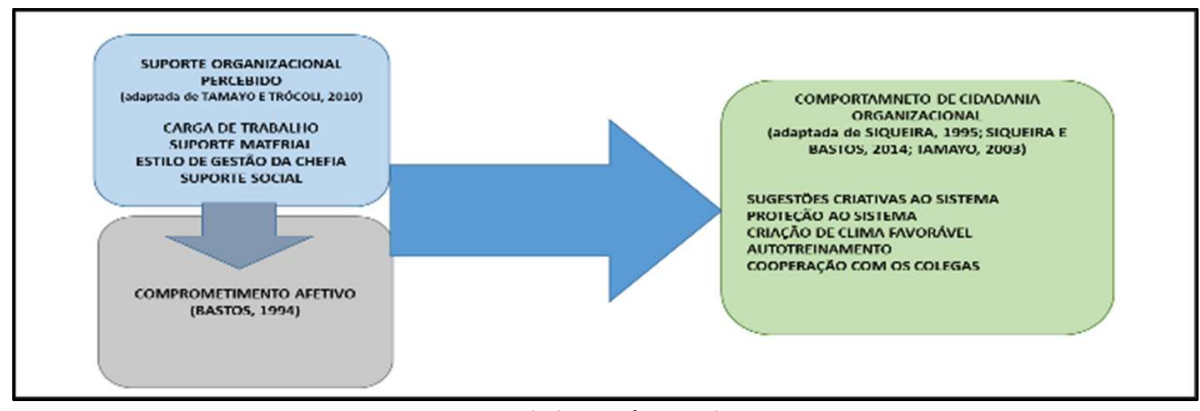

Figura 1: Modelo Teórico da Pesquisa 
Resumo das hipóteses da Pesquisa: H1: A Percepção de Suporte Organizacional está positivamente e significativamente relacionada com o Comportamento de Cidadania Organizacional; H2: A Percepção de Suporte Social está positivamente e significativamente relacionada com o Comportamento de Cidadania Organizacional; H3: A Percepção de Suporte Organizacional está positivamente e significativamente relacionada com o Comprometimento Afetivo; H4: A Percepção de Suporte Social está positivamente e significativamente relacionada com o Comprometimento Afetivo; H5: O Comprometimento Afetivo influencia positivamente e significativamente o Comportamento de Cidadania Organizacional; e H6: Os cinco fatores de cidadania organizacional estão mais fortemente associados ao Comprometimento Afetivo do que aos Suportes Organizacional e Social.

\section{RESULTADOS}

Com o objetivo de sistematizar a discussão, os resultados serão apresentados na seguinte sequência: Perfil da Amostra, Análise Fatorial e Correlação entre os Construtos. Pelo resultado da análise sociodemográfica constatou-se que a amostra teve uma composição de $50 \%$ do sexo masculino e $50 \%$ do sexo feminino. A média de idade foi 41,4 anos com desvio padrão de 10,7 . Quanto a escolaridade, $29,4 \%$ da amostra possuía Especialização, seguido de perto por 28,1\% que possuem Mestrado, 18,4\% Doutorado, 17,1\% Graduação e apenas 7,1\% possuíam somente o Ensino Médio. Quanto ao cargo 71,6\% eram Técnicos Administrativos e $28,4 \%$ eram Professores. Quanto à função, $72,3 \%$ dos respondentes não ocupavam função de chefia no momento da coleta de dados.

\section{Análise Fatorial}

Inicialmente verificou-se a adequação da utilização da análise fatorial por meio dos testes KaiserMeyer-Olkin (KMO) e do de Bartlett. O índice KMO de adequação da amostra é apropriado quando o resultado encontrado for maior ou igual a 0,5 , de forma que a correlação entre os pares de variáveis seja explicada pelas demais variáveis do estudo (MALHORTA, 2006); e o teste de esfericidade de Bartlett é significativo se apresentar valor inferior a 0,0001.

Nesta pesquisa o teste de KMO mostrou-se satisfatório para todas as escalas. Na escala de cidadania organizacional o KMO foi de 0,893; já na escala de comprometimento afetivo o valor encontrado foi de 0,894 ; e para a escala de suporte organizacional o KMO foi de 0,894. O teste de esfericidade de Bartlett também apresentou resultado significativo nas três escalas.

O construto cidadania organizacional apresentou bom agrupamento das variáveis nos fatores, conforme havia sido previamente determinado. A análise da variância explicada para a escala de cidadania organizacional revelou que $61,7 \%$ da variância da escala é explicada por meio da divisão dos itens em 5 fatores, o que corrobora com a literatura (SIQUEIRA, 1995; PORTO et al., 2003).

Para a escala de Suporte Organizacional Percebido (ESOP) algumas variáveis apresentaram agrupamento diferente daquele sugerido por Tamayo et al. (2010). Duas variáveis do fator Suporte Material ('esta organização deixa faltar materiais necessários ao desenvolvimento do meu trabalho' e 'esta 
organização fornece equipamentos de má qualidade') agruparam-se no fator Sobrecarga de Trabalho. O fator Sobrecarga de Trabalho, por outro lado, apresentou uma variável que não estava se adequando ao fator sendo então retirada da análise, sendo ela 'no meu trabalho há pressão quanto ao prazo para se completar as tarefas'. No final o fator Sobrecarga de Trabalho ficou com 5 itens. A variância explicada foi de 57,24\%, dividida em 4 fatores.

Para analisar a confiabilidade dos fatores utilizou-se o teste Alpha de Cronbach. A escala de cidadania organizacional apresentou, no geral, uma confiabilidade de 0,93 . Com relação aos fatores a confiabilidade encontrada foi a seguinte: no fator Defesa da Organização o valor foi 0,88 ; no fator Apresentação de Sugestões Criativas o valor foi 0,89; para o fator Proteção da Organização foi 0,70 ; para o fator Autotreinamento o valor foi 0,75; e por fim, no fator Cooperação com os colegas o valor foi 0,58. Neste último fator o valor encontrado está abaixo do valor recomendado na literatura, que recomenda um valor mínimo do Alpha de 0,60. No entanto, o valor encontrado nessa amostra está muito próximo do valor mínimo, por isso decidiu-se por manter o fator na análise.

$\mathrm{Na}$ escala de comprometimento afetivo a confiabilidade encontrada foi de 0,94. E na escala de suporte organizacional percebido a confiabilidade geral da escala foi de 0,79; para o fator Estilo de Gestão da Chefia encontrou-se confiabilidade de 0,89; no fator Apoio dos Colegas o valor foi de 0,66; o fator Sobrecarga de Trabalho teve um alpha de 0,74; e o Suporte Material apresentou o valor de 0,79.

\section{Correlação entre os Construtos}

Os coeficientes de correlação de Pearson ( $r$ ) entre os construtos Cidadania Organizacional, Comprometimento Afetivo e Suporte Organizacional Percebido (Suporte Org. + Suporte Social) estão indicados na tabela 1. Observando a tabela é possível afirmar que a relação entre Cidadania e Comprometimento Afetivo é uma relação com força moderada, com valor de 0,479 ; revelando que a relação afetiva do funcionário com a organização interfere diretamente no seu comportamento de cidadania.

Pela tabela 1 também se percebe uma correlação de força moderada entre Cidadania e Suporte Organizacional Percebido, com valor de 0,35. Depreende-se disso que o Suporte Organizacional Percebido (soma do Sup. Organizacional com o Sup. Social), interfere diretamente no comportamento de cidadania, sugerindo que a percepção do apoio da organização, dos colegas de trabalho e da chefia, é determinante para a emissão dos gestos cidadãos na empresa pesquisada. No entanto, comparando com o valor da correlação obtida para o Comprometimento Afetivo, o valor encontrado na correlação para o Suporte Organizacional Percebido é menor. Apontando para a conclusão de que o Comprometimento tem uma interferência maior no Comportamento de Cidadania do que o Suporte.

Entretanto, é preciso destacar ainda, que entre os dois componentes do Suporte Percebido, o Suporte Organizacional e o Suporte Social, é o Suporte Social que tem maior influência sobre a Cidadania Organizacional, com valor de força moderada de 0,320. Isso implica que, na percepção dos pesquisados, o apoio dos colegas e da chefia é fundamental para a emissão do seu comportamento de cidadania. Ou até 
mesmo, que esses funcionários percebem a atuação da organização por meio da relação com os seus pares e com seus chefes, e é essa relação que estimula a emissão dos atos de cidadania.

A análise da tabela 1, também revela uma correlação forte entre Comprometimento Afetivo e Suporte Organizacional Percebido, com valor de 0,520. Esse resultado demonstra que os funcionários da organização pesquisada percebem que tem apoio da organização e que esta cumpre com todas as suas obrigações de empregadora, resultando numa ligação afetiva forte do funcionário com o seu trabalho.

Tabela 1: Coeficientes de Correlação ( $r$ de Pearson) entre os construtos Cidadania Organizacional, Comprometimento Afetivo e Suportes Organizacional e Social.

\begin{tabular}{|c|c|c|c|c|c|}
\hline & CIDADANIA & $\begin{array}{c}\text { COMPROM. } \\
\text { AFETIVO }\end{array}$ & $\begin{array}{c}\text { SUPORTE } \\
\text { PERCEBIDO }\end{array}$ & $\begin{array}{c}\text { SUPORTE } \\
\text { ORG. }\end{array}$ & $\begin{array}{c}\text { SUPORTE } \\
\text { SOCIAL }\end{array}$ \\
\hline CIDADANIA & -------- & 0,479 & 0,350 & 0,205 & 0,320 \\
\hline COMPROM. AFETIVO & 0,479 & ---------- & 0,520 & 0,278 & 0,490 \\
\hline SUPORTE PERCEBIDO & 0,350 & 0,520 & -------- & 0,610 & 0,900 \\
\hline SUPORTE ORG. & 0,205 & 0,278 & 0,610 & $\begin{array}{l}------- \\
\end{array}$ & 0,204 \\
\hline SUPORTE SOCIAL & 0,320 & 0,520 & 0,900 & 0,204 & $\begin{array}{l}------ \\
\end{array}$ \\
\hline
\end{tabular}

Na tabela 2, encontram-se os valores das correlações dos construtos com cada fator de cidadania organizacional. Por essa tabela o Fator 1 (Defesa da Organização) tem uma correlação muito forte com o Comprometimento Afetivo, com valor de 0,713 e moderada com o Suporte Percebido, com valor de 0,382. Portanto, o fator Defesa da Organização sofre uma influência determinante do Comprometimento Afetivo, revelando que para os funcionários dessa organização a ligação afetiva forte com o seu trabalho leva-os a atuarem em defesa da organização, contribuindo para a boa reputação da empresa no ambiente externo.

O Fator 2 (Sugestões Criativas) apresenta correlação moderada com o Comprometimento Afetivo, com valor de 0,254 e correlação fraca de 0,227 com o Suporte Percebido. Novamente é o Comprometimento Afetivo com a organização que interfere de maneira decisiva para que o funcionário apresente sugestões de melhoria no seu ambiente de trabalho. Quanto mais comprometido com a organização mais motivado ele se sente para expressar suas ideias e pensamentos.

Os Fatores 3 (Proteção ao Sistema) e 4 (Autotreinamento) têm correlação fraca tanto com o Comprometimento quanto com o Suporte, sendo de 0,217; 0,198; 0,224 e 0,169, respectivamente. Este resultado revela que para a amostra analisada os construtos Comprometimento Afetivo e Suporte Organizacional não influenciam de maneira significativa a atuação do funcionário na preservação do seu ambiente de trabalho e na busca de mais capacitação e treinamento. Sendo necessário que outros estudos sejam realizados com o objetivo de identificar essa relação.

Já o Fator 5 (Cooperação com os colegas) apresentou correlação fraca com o Comprometimento e moderada com o Suporte, sendo de 0,232 e 0,257, respectivamente. Nesse caso, ficou comprovado que o Fator Cooperação com o Colegas sofre maior influência do Suporte Organizacional Percebido, o que é algo diferente do que foi encontrado por Siqueira (2003). Segundo Siqueira (2003), os fatores que compõem a cidadania não apresentavam boa correlação com o suporte organizacional. Neste trabalho, entretanto, utilizou-se o Suporte Social em conjunto com o Organizacional, e parece ter sido esta a diferença. $\mathrm{O}$ apoio dos colegas e da chefia se revelaram como elemento determinante para o comportamento de cooperação no ambiente de trabalho. 
Este resultado também é importante para responder ao questionamento levantado por Costa et al. (2015), onde questiona "quais os antecedentes para os atos de cooperação com os colegas?", tendo em vista que eles não encontraram valor significativo de correlação entre o fator e os construtos analisados (Satisfação com o trabalho e Comprometimento Afetivo). Portanto, de acordo com o estudo em tela, parece que o Suporte Social se constitui num bom antecedente para o fator cooperação com os colegas, e deve ser mais bem investigado em outros estudos.

Tabela 2: Coeficientes de Correlação ( $r$ de Pearson) entre os cinco fatores de Cidadania Organizacional, Comprometimento Afetivo e Suportes Organizacional e Social.

\begin{tabular}{|l|c|c|c|c|}
\hline FATORES & $\begin{array}{c}\text { COMPROM. } \\
\text { AFETIVO }\end{array}$ & $\begin{array}{c}\text { SUPORTE } \\
\text { PERCEBIDO }\end{array}$ & $\begin{array}{c}\text { SUPORTE } \\
\text { ORG. }\end{array}$ & 0,241 \\
\hline FATOR 1 & 0,713 & 0,382 & 0,136 & 0,339 \\
\hline FATOR 2 & 0,254 & 0,227 & 0,077 & 0,206 \\
\hline FATOR 3 & 0,217 & 0,198 & 0,101 \\
\hline FATOR 4 & 0,224 & 0,169 & 0,147 & 0,153 \\
\hline FATOR 5 & 0,232 & 0,257 & 0,237 \\
\hline
\end{tabular}

Outro ponto relevante e que deve ser considerado é a correlação entre os fatores que compõem o construto cidadania organizacional. A análise da Tabela 3 mostra que há uma correlação de moderada a forte $(0,252$ a 0,522) entre os fatores. Evidenciando uma consistência interna entre os itens que constituem o comportamento de cidadania organizacional. Este resultado é diferente do encontrado por Martins et al. (2015), que encontraram uma correlação fraca entre os fatores de cidadania, e afirmam haver um problema na dimensionalidade do construto. Dessa forma, considera-se que a boa correlação entre os fatores de cidadania constitui um achado importante deste trabalho.

Tabela 3: Correlação entre os fatores de Cidadania Organizacional.

\begin{tabular}{|c|c|c|c|c|c|}
\hline & FATOR 1 & FATOR 2 & FATOR 3 & FATOR 4 & 0,361 \\
\hline FATOR 1 & 1 & 0,437 & 0,293 & 0,337 \\
\hline FATOR 2 & 0,437 & 1 & 0,337 & 0,522 \\
\hline FATOR 3 & 0,293 & 0,337 & 1 & 0,252 & 1 \\
\hline FATOR 4 & 0,361 & 0,522 & 0,252 & 0,327 \\
\hline FATOR 5 & 0,337 & 0,491 & 0,327 & 0,317 \\
\hline
\end{tabular}

Considera-se, portanto, que os resultados deste estudo contribuem para o estudo do Comportamento de Cidadania Organizacional em âmbito nacional. Primeiramente, porque confirma o Comprometimento Afetivo como um antecedente para este tipo de comportamento. E ainda, porque apresenta o Suporte Social como um antecedente importante para o fator Cooperação, evidenciando a importância do apoio dos colegas e da chefia no ambiente de trabalho. E finalmente, por apresentar uma boa correlação entre os fatores de cidadania, mostrando que esses fatores possuem certa consistência interna.

\section{DISCUSSÃO}

Após a apresentação dos resultados dos testes estatísticos é preciso fazer algumas discussões, por meio de uma análise dos resultados em confronto com as hipóteses deste estudo e com a literatura apresentada no referencial teórico. As primeiras hipóteses deste trabalho estão relacionadas com o Comportamento de Cidadania Organizacional e a Percepção de Suportes Organizacional e Social: H1: A 
Percepção de Suporte Organizacional está positivamente e significativamente relacionada com o Comportamento de Cidadania Organizacional; e H2: A Percepção de Suporte Social está positivamente e significativamente relacionada com o Comportamento de Cidadania Organizacional.

Os resultados apresentados para a correlação de Pearson, mostraram que há sim uma relação positiva e significativa entre a Percepção de Suporte Organizacional e o Comportamento de Cidadania Organizacional, o que leva a aceitação da hipótese 1 deste estudo. Para a Percepção de Suporte Social e Cidadania Organizacional, o resultado também revelou que há uma correlação positiva e significativa entre os construtos, fazendo com que a Hipótese 2 também fosse aceita.

As outras duas hipóteses deste estudo se referiam a relação dos Suportes Organizacional e Social com o Comprometimento Afetivo: H3: A Percepção de Suporte Organizacional está positivamente e significativamente relacionada com o Comprometimento Afetivo; e H4: A Percepção de Suporte Social está positivamente e significativamente relacionada com o Comprometimento Afetivo.

No caso dessas duas hipóteses os resultados encontrados na análise da correlação de Pearson indicaram uma relação positiva e significativa entre os construtos, confirmando então, as hipóteses 3 e a 4. Entretanto, a relação mais forte foi verificada entre o Suporte Social e o Comprometimento Afetivo, revelando que o apoio recebido da chefia e dos colegas de trabalho influenciam fortemente no Comprometimento Afetivo do funcionário.

A hipótese cinco deste estudo objetiva verificar a relação existente entre o Comprometimento Afetivo e a Cidadania Organizacional: H5: O Comprometimento Afetivo influencia positivamente e significativamente o Comportamento de Cidadania Organizacional. Pela análise de correlação de Pearson há uma relação positiva e significativa entre o Comprometimento Afetivo e a Cidadania Organizacional, resultando na aceitação da hipótese acima. Esse resultado confirma o que foi dito no referencial teórico, especialmente quanto aos estudos publicados de Siqueira (2003) e Williams et al. (1991), corroborando com a afirmativa de que um funcionário que se sente comprometido afetivamente com a organização está mais propenso a realizar gestos de cidadania no ambiente de trabalho.

A última hipótese deste estudo testa a relação dos fatores de cidadania com cada um dos construtos em estudo: H6: Os cinco fatores de cidadania organizacional estão mais fortemente associados ao Comprometimento Afetivo do que aos Suportes Organizacional e Social. Os resultados encontrados neste estudo permitem aceitar parcialmente a hipótese 6. Apenas o fator Defesa da Organização apresentou correlação forte com o Comprometimento Afetivo. O fator Sugestões Criativas apresentou correlação moderada; e os fatores Autotreinamento e Proteção ao Sistema tiveram correlação fraca com o Comprometimento.

No entanto, o resultado mais inesperado foi do fator Cooperação com os colegas que apresentou correlação moderada com o Suporte Organizacional Percebido, sendo esta relação determinada mais fortemente pelo Suporte Social. Dessa forma, este resultado contradiz o resultado encontrado por Siqueira (2003) em seu modelo pós-cognitivo. Segundo Siqueira (2003) os cinco fatores de cidadania estão mais 
fortemente associados às variáveis afetivas (Comprometimento Afetivo) do que com as cognitivas (Suporte Organizacional).

No estudo aqui realizado encontrou-se uma correlação maior entre o Suporte Organizacional Percebido e o fator Cooperação, especialmente essa relação foi maior devido a presença do Suporte Social no Suporte Organizacional Percebido, revelando que para os funcionários da organização analisada o apoio dos colegas e da chefia é condição essencial para a existência de Cooperação no ambiente de trabalho. De maneira geral, os resultados encontrados pela Correlação de Pearson remetem a compreensão de que os suportes organizacional e social, e o comprometimento afetivo influenciam positivamente os comportamentos de cidadania organizacional.

\section{CONSIDERAÇÕES FINAIS}

Tendo em vista que o Comportamento de Cidadania Organizacional tem sido pouco investigado em âmbito nacional, quando se compara à quantidade de estudos realizados no contexto internacional, e também que a identificação dos antecedentes e consequentes deste comportamento necessita de uma maior compreensão, este estudo analisou a influência do Comprometimento Afetivo e dos Suportes Organizacional e Social sobre o Comportamento de Cidadania Organizacional, segundo a perspectiva dos servidores públicos de uma instituição federal de ensino.

Inicialmente, realizou-se uma análise fatorial exploratória que, de maneira geral, mostrou que cada uma das escalas utilizadas (Comportamento de Cidadania Organizacional, Comprometimento Afetivo e Suporte Organizacional Percebido), apresentou adequação e confiabilidade dos fatores obtidos, com exceção do fator Cooperação que apresentou confiabilidade um pouco abaixo do valor mínimo exigido.

Em seguida foi feito o teste de Correlação de Pearson para verificar a relação existente entre Cidadania Organizacional, Comprometimento Afetivo e Suporte Organizacional Percebido, o resultado obtido indicou haver uma associação positiva entre todas as variáveis em estudo, tendo sido corroborada a maioria das hipóteses desta pesquisa $(\mathrm{H} 1, \mathrm{H} 2, \mathrm{H} 3, \mathrm{H} 4$ e H5). Cabe ressaltar a relação forte entre o Comprometimento Afetivo e a Cidadania Organizacional, indicando que há uma identificação do funcionário com os objetivos e com os valores organizacionais, por meio de um sentimento de lealdade e de se esforçar pela organização que influenciam positivamente nas atitudes de cidadania

No que se refere aos fatores que compõem o Comportamento de Cidadania, especial destaque deve ser dado ao fator Cooperação, que apresentou uma relação significativa com o Suporte Social. Esperava-se que a relação fosse mais forte com o Comprometimento Afetivo, entretanto, o resultado encontrado sugere que o ato de colaborar, de se preocupar com o outro, de se colocar à disposição para ajudar quando os outros necessitam está diretamente relacionado com o apoio que se recebe dos próprios colegas e também da chefia. Um ambiente positivo, em que haja respeito e afeto, é determinante para que o funcionário tenha mais disposição para cooperar.

Por outro lado, os fatores ‘Defesa da Organização' e 'Sugestões criativas' apresentaram relação direta com o Comprometimento Afetivo, enquanto que os fatores 'Autotreinamento' e 'Proteção ao sistema' não 
apresentaram correlação significativa com nenhum dos construtos analisados. Estes resultados revelam que os fatores do Comportamento de Cidadania apresentam influencias em bases diferentes, sendo que dois fatores não apresentaram correlação alguma com os construtos em tela, necessitando de mais estudos para se identificar essa relação. Com estes resultados a hipótese 6, que previa uma forte relação do Comprometimento afetivo com todos os fatores da Cidadania, foi confirmada apenas parcialmente.

Portanto, pesquisas futuras devem investigar mais a fundo os antecedentes para os fatores 'Proteção ao Sistema' e 'Autotreinamento'. Sugere-se também, a ampliação do entendimento sobre a importância do Suporte Social para o Comportamento de Cidadania Organizacional, utilizando-se de métodos de Regressão Múltipla. Outra sugestão é a realização de estudos qualitativos que aprofundem as investigações sobre as interações no contexto social de trabalho e os comportamentos de cidadania organizacional, especialmente no que tange a atuação da chefia e dos colegas de trabalho, buscando uma maior compreensão dos fenômenos investigados, tendo como referência primordial a subjetividade dos indivíduos.

Dessa forma, estudos que investiguem os motivos que levam os funcionários a praticarem este tipo de ato são de suma importância para as organizações, e em especial para as organizações públicas. Pois, segundo Vigoda et al. (2001), a cidadania é uma construção vital para o serviço público, pois promove um ambiente mais saudável, uma burocracia mais eficiente e estimula a vida em comunidade.

\section{REFERÊNCIAS}

ANDRADE, T.; ESTIVALETE, V. F. B.; COSTA, V. F.. Comportamentos de Cidadania Organizacional, Confiança e Suporte Organizacional: Proposição de um Framework de Análise. In: ENCONTRO NACIONAL DA ASSOCIAÇÃO NACIONAL DE PÓS-GRADUAÇÃO E PESQUISA EM ADMINISTRAÇÃO, 39. Anais. Belo Horizonte: ANPAD, 2015.

BASTOS, A. V. B.. Comprometimento no Trabalho: os caminhos da pesquisa e os seus desafios metodológicos. Trabalho, organizações e cultura, p.94-109, 1996.

BOREHAM, N.; FISCHER, M.; SAMURCAI, R.. Routledge: 2013. CHEN, Z.; EISENBERGER, R.; JOHNSON, K. M.; SUCHARSKI, I. L.; ASELAGE, J.. Perceived Organizational Support and ExtraRole Performance: Which Leads to Which?. The Journal of social psychology, v.149, n.1, p.119-124, 2009.

COHEN, A.; VIGODA, E.. Do Good Citizens Make Good Organizational Citizens? An Empirical Examination of the Relationship Between General Citizenship and Citizenship Organizational Behavior in Israel. Administration \& Society, v.32, n.5, p.596-624, 2000.

COSTA, V. F.; ANDRADE, T.. Comportamento de cidadania organizacional: Caracterização da produção científica internacional no período de 2002 a 2012. Revista de Administração Mackenzie, v.16, n.2, 2014

DEKAS, K. H.. Citizenship in context: investigating the effects of work group climate on organizational citizenship perceptions and behavior. Tese (Doutorado) - The University of Michigan, Ann Arbor, 2010.
DYNE, L.; CUMMINGS, L. L.; PARKS, J. M.. Extra-role behaviors-in pursuit of construct and definitional clarity (a bridge over muddied waters). Research in organizational behavior, v.17, p.215-285, 1995.

EISENBERGER, R.; FASOLO, P.; DAVIS-LAMASTRO, V.. Perceived organizational support and employee diligence, commitment, and innovation. Journal of applied psychology, v.75, n.1, p.51, 1990.

FERNANDES, C. M; SIQUEIRA, M. M. M.; VIEIRA, A. M.. Impacto da percepção de suporte organizacional sobre o comprometimento organizacional afetivo: o papel moderador da liderança. Revista Pensamento Contemporâneo em Administração, v.8, n.4, p.140, 2014.

FOSSÁ, M. I. T.. A cultura de devoção nas empresas familiares e visionárias: uma definição teórica e operacional. Tese (Doutorado) - Universidade Federal do Rio Grande do Sul, Porto Alegre, 2003.

FREITAS, H.. O método de pesquisa survey. Revista de Administração, v.35, n.3, p.105-112, 2000.

GOMES, A. C. P.; BASTOS, A. V. B.; MENDONÇA FILHO, E. J.; MENEZES, I. G.. Cidadania e cidadania organizacional: Questões teóricas e conceituais que cercam a pesquisa na área. Estudos e Pesquisas em Psicologia, v.14, n.3, p.711731, 2014.

HAIR, J. F.; BLACK, W. C.; BABIN, B. J.; ANDERSON, R.; THATM, R.. Análise multivariada de dados. Rio de Janeiro: Bookman, 2009. 
KAMDAR, D.; DYNE, L.. The joint effects of personality and workplace social exchange relationships in predicting task performance and citizenship performance. Journal of applied psychology, v.92, n.5, p.1286, 2007.

KATZ, D.; KAHN, R. L.. Psicologia social das organizações. São Paulo: Atlas, 1974

KIM, Y. J.; DYNE, L.; KAMDAR, D.; JOHSON, R. E.. Why and when do motives matter? An integrative model of motives, role cognitions, and social support as predictors of OCB. Organizational Behavior and Human Decision Processes, v.121, n.2, p.231-245, 2013.

MARÔCO, J.. Análise estatística com o SPSS Statistics. Pinheiro: ReportNumber, 2011.

MARTINS, V.; COSTA, L. V.; SIQUEIRA, M. M. M.. O Impacto do Comprometimento Afetivo e do Engajamento No Trabalho Sobre Os Comportamentos de Cidadania Organizacional. Revista de Administração, Contabilidade e Economia da FUNDACE, v.6, n.2, p.1-13, 2015.

\section{MEDEIROS, S. B.. Percepção de suporte e} comprometimento organizacional: um estudo nas unidades de criminalística da Polícia Federal. Tese (Doutorado) Fundação Getúlio Vargas, Rio de Janeiro, 2013.

MEYER, J. P.; ALLEN, N. J.; SMITH, C. A.. Commitment to organizations and occupations: Extension and test of a three-component conceptualization. Journal of applied psychology, v.78, n.4, p.538, 1993

OLIVEIRA-CASTRO, G. A.; PILATI, R.; BORGES-ANDRADE, J. E.. Percepção de suporte organizacional: desenvolvimento e validação de um questionário. Revista de Administração Contemporânea, v.3, n.2, p.29-51, 1999.

ORGAN, D. W.. Organizational citizenship behavior: The good soldier syndrome. New York: Lexington Books, 1988.

PASCHOAL, T.; TORRES, C. V.; PORTO, J. B.. Felicidade no Trabalho: Relações com Suporte Organizacional e Suporte Social. Revista de Administração Contemporânea, v.14, n.6, p.1054, 2010.

PINHEIRO, F. A.. Aspectos psicossociais dos distúrbios osteomusculares relacionados ao trabalho-DORT LER. Tese (Doutorado) - Universidade de Brasília, Brasília, 2002.

PODSAKOFF, N. P.; PODSAKOFF, P. M.; MACKENZIE, S. B. MAYNES, T. D.; SPOELMA, T. M.. Consequences of unit-level organizational citizenship behaviors: A review and recommendations for future research. Journal of Organizational Behavior, v.35, n.1, p.87-119, 2014.

PODSAKOFF, P. M.; MACKENZIE, S. B.; PAINE, J. B.; BACHRACH, D. G.. Organizational Citizenship Behaviors: A Critical Review of the Theoretical and Empirical Literature and Suggestions for Future Research. Journal of Management. v.26, n.3, p.513-563, 2000.

PORTO, J. B.; TAMAYO, A.. Desenvolvimento e validação da escala de civismo nas organizações. Estudos de Psicologia, v.8, n.3, p.393-402, 2003.

RAYNER, J.; LAWTON, A.; WILLIAMS, H. M.. Organizational citizenship behavior and the public service ethos: Whither the organization?. Journal of business ethics, v.106, n.2, p.117-130, 2012

RHOADES, L.; EISENBERGER, R.. Perceived Organizational Support: a review of the literature. Journal of Applied Psychology, v.87, n.4, p.698-714, 2002.

SIQUEIRA, M. M. M.. Antecedentes de comportamentos de cidadania organizacional: a análise de um modelo póscognitivo. Tese (Doutorado) - Universidade de Brasília, Brasília, 1995.

SIQUEIRA, M. M. M.. Proposição e análise de um modelo para comportamentos de cidadania organizacional. Revista de Administração Contemporânea, v.7, p.165-184, 2003.

SIQUEIRA, M. M. M.; GOMIDE JUNIOR, S.. Vínculos do indivíduo com o trabalho e com a organização. Psicologia, organizações e trabalho no Brasil, p.300-330, 2004.

TAMAYO, M. R.; PINHEIRO, F. A.; TRÓCOLI, B. T.; PAZ, M. G. T.. Construção e validação da escala de suporte organizacional percebido (ESOP). In: REUNIÃO ANUAL DA SBPC, 52. Anais. Brasília: 2000.

VIGODA, E; GOLEMBIEWSKI, R. T.. Citizenship behavior and the spirit of new managerialism: A theoretical framework and challenge for governance. The American Review of Public Administration, v.31, n.3, p.273-295, 2001.

WILLIAMS, L. J.; ANDERSON, S. E.. Job satisfaction and organizational commitment as predictors of organizational citizenship and in-role behaviors. Journal of management, v.17, n.3, p.601-617, 1991.

A CBPC - Companhia Brasileira de Produção Científica (CNPJ: 11.221.422/0001-03) detém os direitos materiais desta publicação. Os direitos referem-se à publicação do trabalho em qualquer parte do mundo, incluindo os direitos às renovaç̃es, expansões e disseminações da contribuiç̃o, bem como outros direitos subsidiários. Todos os trabalhos publicados eletronicamente poderão posteriormente ser publicados em coletâneas impressas sob coordenação da Sustenere Publishing, da Companhia Brasileira de Produção Científica e seus parceiros autorizados. Os (as) autores (as) preservam os direitos autorais, mas não têm permissão para a publicação da contribuição em outro meio, impresso ou digital, em português ou em tradução. 